\title{
APRESENTAÇÃO DO NÚMERO
}

\author{
Marlene Matos \\ Celina Manita \\ Miguel M. Gonçalves \\ Rui Abrunhosa Gonçalves \\ Carla Martins
}

Este número especial é dedicado a Carla Machado. Não sendo possível contemplar numa só edição o seu vasto leque de interesses, quisemos partilhar com o leitor parte do legado científico da autora, que deixou marcas profundas na história da Psicologia da Justiça, da Criminologia e da Vitimologia em Portugal. Organizado a partir de um conjunto de trabalhos planeados e desenhados com a Carla, escritos agora pelos seus colegas, estudantes e investigadores, privilegiámos neste número os domínios de interesse e investigação a que se começara a dedicar mais recentemente. Por essa razão, a vertente da Psicologia Forense, que tão trabalhada foi por ela e já extensamente retratada em artigos de revistas e em obras publicadas nos últimos 10 anos, quase não é abordada neste número especial da Revista Psicologia.

Nascida a 21 de setembro de 1968, em Vila Real, Carla Machado concluiu, em 1990, a Licenciatura em Psicologia pela Faculdade de Psicologia e Ciências da Educação da Universidade do Porto, na pré-especialização de Psicologia do Comportamento Desviante. Começou por ser Psicóloga no Gabinete de Psicologia "Psinova" e, posteriormente, Psicóloga e Professora de Psicologia na Cooperativa de Ensino Didáxis, mas por muito pouco tempo. Logo em 1992 ingressa no Instituto de Reinserção Social (atual DGRSP), na delegação do Porto, como Técnica Superior de Reinserção Social, desempenhando, simultaneamente, funções de apoio técnico e de supervisão na execução de perícias sobre a personalidade.

Em 1993, a pós-graduação em Criminologia que realizou na Faculdade de Psicologia e Ciências da Educação da Universidade do Porto, com uma monografia intitulada "Perigosidade criminal", pressagiava já o seu notável 
trajeto enquanto investigadora. Desde então, frequentou vários cursos breves, workshops e seminários temáticos, ingressando na Academia em 1995 enquanto bolseira de doutoramento do então Instituto de Educação e Psicologia da Universidade do Minho. Iniciou quase de imediato aquilo que viria a ser uma carreira académica brilhante, na qualidade de Assistente Convidada do Departamento de Psicologia da mesma Universidade. Em 2000, finalizou o seu Doutoramento em Psicologia, na Universidade do Minho, na área de conhecimento de Psicologia da Justiça, com a dissertação "Discursos do medo, imagens do 'Outro'. Estudos sobre insegurança urbana na cidade do Porto", orientada pelo Prof. Doutor Cândido da Agra e posteriormente publicada em livro. Desde então, a convite, lecionou em várias universidades do país sobre os diversos temas a que se dedicava.

No seu percurso destaca-se o envolvimento, enquanto investigadora responsável, em projetos de investigação nacional, apoiados pela Fundação para a Ciência e a Tecnologia e pela União Europeia, em áreas complementares entre si: Enquadramento cultural da violência contra mulheres e crianças, Violência no namoro, Vitimação múltipla de mulheres socialmente excluídas, entre outros. Fez também parte de várias equipas nacionais, nomeadamente, dos Grupos de Ajuda Mútua (GAM), do Observatório Permanente de Segurança do Porto e do projeto "O consumo de drogas em contexto natural".

O seu mérito levou a que fosse eleita como consultora de vários projetos nos domínios da sua especialidade. Em 2008 foi proposta pelo Governo Português como Perita para integrar o Group of Experts on Action against Trafficking in Human Beings, do Conselho da Europa. Participou, ainda, ativamente na elaboração de relatórios técnico-científicos, na qualidade de especialista nacional, nomeadamente, sobre adoção, sobre prevenção da violência doméstica e a proteção e assistência às suas vítimas e, ainda, sobre os Sistemas de Acolhimento, de Proteção e Tutelar de Crianças e Jovens.

O seu trabalho refletiu-se em inúmeras conferências plenárias e comunicações científicas, nacionais e internacionais, onde revelou uma extraordinária capacidade como oradora.

Da extensa obra publicada em Portugal destaca-se o Manual de Psicologia Forense (Psiquilibrios Edições), Vitimologia: Das novas abordagens teóricas às novas práticas de intervenção com vítimas (Psiquilibrios Edições), Novas formas de vitimação criminal (Psiquilibrios Edições), Crime e insegurança. Discursos do medo, imagens do "outro" (Editorial Notícias), Violência e vitimas de crimes - Vol I e II (Quarteto), Manual da Escala de Crenças sobre Violência Conjugal (E.C.V.C.) e do Inventário de Violência Conjugal (I.V.C.) (Psiquilibrios Edições) e Manual da Escala de Crenças sobre Punição Física (E.C.P.F.) e do Inventário de Práticas Educativas Parentais (I.P.E.) (Psiquilibrios Edições). 
Em 2009 tornou-se uma das coorganizadoras da publicação periódica Instrumentos e contextos de avaliação psicológica (Almedina) e, em 2010, passa a coordenar a coleção "Psicologia da Justiça" (Psiquilibrios Edições).

Entre as várias publicações internacionais, destacam-se os seus trabalhos no International Handbook of Victimology (2010, Knepper \& S. G. Shoham), Journal of Family Violence, Integrative Psychological \& Behavioral Science e Child Abuse \& Neglect. Foi, ainda, revisora Adhoc de várias revistas nacionais e internacionais, entre as quais, Spanish Journal of Psychology, Journal of Family Violence, European Journal of Psychology Applied to Legal Context, Child Abuse \& Neglect.

Em paralelo, estabeleceu uma rede privilegiada de intercâmbio científico que se traduziu, mais tarde, em inúmeras colaborações com equipas e projetos de investigação fora do nosso país. Nesse contexto, foi coordenadora, em Portugal, do estudo International Perspectives on War and Peace, sob coordenação geral da Prof ${ }^{a}$ Kathleen Malley-Morrison (Boston University). Integrou, também, o projeto Risktaking Online Behaviour Empowerment through Research and Training (ROBERT), financiado pela União Europeia, e o Delphi Study - Global effort to improve measurement of child maltreatment, financiado pela International Society for the Prevention of Child Abuse and Neglect (ISPCAN).

A sua afirmação na investigação científica, associada à consistência, inovação e criatividade que sempre revelou, levaram-na a orientar vários trabalhos de mestrado e doutoramento. Das atividades académicas desenvolvidas, há ainda a destacar a sua participação em inúmeros júris de provas e concursos académicos.

O seu percurso foi igualmente marcado por funções de gestão universitária, tendo sido Coordenadora da especialização em Psicologia da Justiça do Mestrado Integrado em Psicologia da Universidade do Minho e Diretora do Curso de Psicologia da Universidade do Minho.

O seu constante cuidado em conciliar a vida académica, a investigação e a prática, levaram-na a integrar o Serviço de Psicologia da Universidade do Minho, em 1998, onde desempenhou funções de psicoterapeuta (individual e de grupo) junto de vítimas de crime e de supervisora científica de todos os casos de avaliação forense de menores, bem como dos processos de psicoterapia com menores, no âmbito da Unidade de Consulta em Psicologia da Justiça desse serviço. A este nível, e preocupada sempre com uma psicologia aplicada baseada no conhecimento científico, deu, com o seu trabalho, um contributo decisivo para os desenvolvimentos recentes ao nível da Psicologia Forense em Portugal.

Mas o pensamento e a voz da Carla não se "ouviram" apenas na Academia. Como cronista, os seus textos quinzenais no Jornal Público traduziam a sua inquietação e espírito cívico, ora democratizando o saber científico, ora 
partilhando episódios do seu quotidiano. Revelador do seu talento imenso e qualidades para a escrita não científica, os seus leitores liam atentamente as crónicas inspiradoras e emocionadas, repletas de significados autênticos partilhados com todos.

Este número especial procura refletir o investimento da Carla Machado em âmbitos diversos mas, ao mesmo tempo, dialogantes, trabalhos com inumeráveis implicações políticas e sociais, como era sempre sua preocupação. Apesar de uma carreira interrompida cedo demais, com a sua morte em 8 de fevereiro de 2011, o contributo da Carla é incontornável para todos aqueles que trabalham ou investigam nas áreas da Psicologia da Justiça, da Vitimologia, da Criminologia, e se empenham no desenvolvimento de boas práticas profissionais.

Este número integra um conjunto de trabalhos em que a Carla Machado esteve envolvida nos últimos anos da sua vida. São, maioritariamente, estudos que estavam, na altura, a ser desenvolvidos no âmbito de projetos de doutoramento.

O primeiro artigo - "Intervenção no fenómeno das drogas: Algumas reflexões e contributos para a definição de boas práticas" - analisa as políticas de intervenção sobre o fenómeno do uso e abuso de drogas ilícitas (uso e abuso de drogas que constituem uma das áreas em que Carla Machado iniciou os seus trabalhos de investigação científica, no final dos anos 80 e início dos anos 90), comparando as lógicas e práticas do proibicionismo e do anti-proibicionismo e refletindo sobre o que atualmente se considera serem boas práticas de intervenção neste fenómeno.

O segundo e o terceiro artigos - respetivamente, "Cidadãos estrangeiros em Portugal: Migrações, crime e reclusão" e "A Psicologia da Paz" -, traduzem um dos focos de atenção mais recentes de Carla Machado: as questões da exclusão social e da violência estrutural. No primeiro discute-se a questão da reclusão, do crime e da imigração, procurando desconstruir estereótipos que relacionam os cidadãos estrangeiros e o crime. No segundo é abordada uma área ainda muito pouco desenvolvida em Portugal - a da Psicologia da Paz e os contributos que os psicólogos poderão dar para a prevenção dos conflitos e para a promoção dos direitos humanos e da paz.

O quarto artigo - "Relações de intimidade juvenis e adultas, uma análise comparativa: Das narrativas de amor às conjugalidades violentas" - procura analisar e desconstruir os discursos sobre o amor e o modo como estes afetam as relações de intimidade, nomeadamente, as violentas, favorecendo ou contrariando a legitimação do uso da violência como tradução de amor, ciúme, paixão. Comparando discursos de vítimas e agressores, adultos e jovens, reflete também sobre as potencialidades do uso destas narrativas ao nível da intervenção. 
O quinto artigo - "Violência nas relações juvenis de intimidade: Uma revisão da teoria, da investigação e da prática" - resume as principais reflexões e resultados do projeto "Violência nas relações juvenis de intimidade", coordenado por Carla Machado, que veio colmatar as lacunas ao nível do conhecimento científico sobre esta forma de violência em Portugal, bem como conferir visibilidade à extensão e à gravidade do fenómeno no país.

Do mesmo projeto, emergiu a implementação em Portugal do programa The Fourth $R$, que visa a prevenção universal da violência no namoro e comportamentos de risco associados, descrito no sexto artigo - "Relacionamentos íntimos juvenis: Programa para a prevenção da violência".

O estudo exploratório "Violência sexual no namoro: Os atletas universitários como grupo de risco?" é um trabalho pioneiro sobre as crenças e comportamentos de violência sexual junto da população atlética universitária e deu origem ao sétimo artigo.

Por último, e porque a violência sexual é um tema central no trabalho desenvolvido por Carla Machado, o oitavo artigo - "A elaboração narrativa no abuso sexual: O papel das vítimas enquanto protagonistas no processo de mudança" - descreve um estudo desenvolvido com vítimas de crimes sexuais, menores de idade, sobre o processo de mudança e as dinâmicas de significação operadas pelas crianças. 